\title{
ERRATUM
}

L. U. Vumazonke $\cdot$ E. A. Pakhomov

P. W. Froneman · C. D. McQuaid

\section{Diet and daily ration of male and female caridean shrimp Nauticaris marionis at the Prince Edward Archipelago}

\section{Polar Biol (2003) 26:420-422}

There has been an error omission on the article. On page 421, paragraph 2 of Results, last sentence, "Cannibalism was rarely reported in females with CL1)." should read
"Cannibalism was rarely reported in females with $\mathrm{CL}<6 \mathrm{~mm}$ but reached $\approx 50 \%$ in the stomachs of the largest females (Fig. 1)." The sentence was correct in the HTML version of the paper.

The online version of the original article can be found at http:// dx.doi.org/10.1007/s00300-003-0492-1

L. U. Vumazonke $(\varangle) \cdot$ P. W. Froneman · C. D. McQuaid

Southern Ocean Group, Department of Zoology and Entomology, Rhodes University, P.O. Box 94 6140, Grahamstown, South Africa

E-mail: 1.vumazonke@ru.ac.za

E. A. Pakhomov

Department of Zoology, Faculty of Science and Technology, University of Fort Hare, Private Bag X1314,

5700 Alice, South Africa

Present address: L. U. Vumazonke

South African Institute for Aquatic Biodiversity,

Private Bag 1015, 6140 Grahamstown, South Africa 